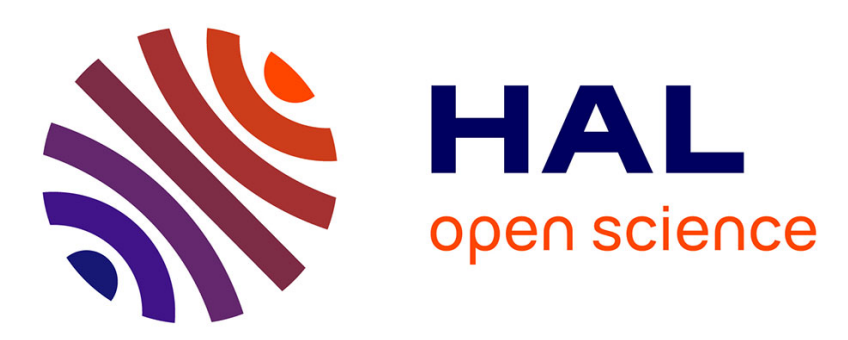

\title{
BIM and PLM: Comparing and Learning from Changes to Professional Practice Across Sectors
}

\author{
J. R. Jupp, M. Nepal
}

\section{To cite this version:}

J. R. Jupp, M. Nepal. BIM and PLM: Comparing and Learning from Changes to Professional Practice Across Sectors. 11th IFIP International Conference on Product Lifecycle Management (PLM), Jul 2014, Yokohama, Japan. pp.41-50, 10.1007/978-3-662-45937-9_5 . hal-01386474

\section{HAL Id: hal-01386474 \\ https://inria.hal.science/hal-01386474}

Submitted on 24 Oct 2016

HAL is a multi-disciplinary open access archive for the deposit and dissemination of scientific research documents, whether they are published or not. The documents may come from teaching and research institutions in France or abroad, or from public or private research centers.
L'archive ouverte pluridisciplinaire HAL, est destinée au dépôt et à la diffusion de documents scientifiques de niveau recherche, publiés ou non, émanant des établissements d'enseignement et de recherche français ou étrangers, des laboratoires publics ou privés.

\section{(c)(1)}

Distributed under a Creative Commons Attribution| 4.0 International License 


\title{
BIM and PLM: Comparing and learning from changes to professional practice across sectors
}

\author{
Jupp JR ${ }^{1}$ and Nepal $\mathrm{M}^{2}$ \\ ${ }^{1}$ University of Technology, Sydney \\ ${ }^{2}$ Queensland University of Technology \\ Julie.Jupp@uts.edu.au; Madhav.Nepal@qut.edu.au
}

\begin{abstract}
This paper presents an analysis of PLM and BIM in relation to effects on professional practice. It draws on the experiences of both communities of practice to explain shifts in professional boundaries. A review of the literature explores the nature of changes triggered by PLM and BIM relative to new activities, roles and responsibilities, knowledge competencies, and relationships. The paper synthesises these changes and reflects PLM and BIM experiences against each other so as to discuss the continuing evolution of professional practice and identify lessons.
\end{abstract}

Keywords: Professional practice, roles and responsibilities, knowledge competencies, stakeholder relations

\section{Introduction}

With the increasing use of building information modelling (BIM), architectural, engineering and construction (AEC) professionals are experiencing radical changes to working practices. BIM as a new technology and approach reflects many of the changes, challenges and opportunities triggered by the introduction of Product Lifecycle Management (PLM) in the aerospace and automotive sectors almost two decades ago. In particular, changes to professional practice relative to the new activities, roles/responsibilities, knowledge competencies, and relationships required during the implementation of PLM, appear to reflect many characteristics reported in the literature on the adoption and deployment of BIM.

The differences between BIM and PLM chiefly surround their capacity for technical and organizational integration, leading to differences in their approach to data governance and information management $[1,2]$. These characteristics together within context-based structural differences highlight other differentiators relative to discipline-based technology applications e.g., differences in tools, BIM/PLM platform specification, and data requirements. However BIM and PLM also share a number of similarities relative to their approach to data sharing, project management, organisation of teams around deliverables and timelines, and object-based visualisation activities. The challenges that follow on from these shared characteristics may provide fertile grounds for sharing lessons learned. Issues surrounding changes to professional practice and cultural change are continuing to plague the practical deployment of both the BIM and PLM concepts across their respective sectors. These challenges stem from a variety of new activities that are changing the nature of professional roles and responsibilities at both the firm and project level. These changes not only require the development of new technical skills but importantly new knowledge competencies and stakeholder relationships.

This paper presents an investigation into BIM and PLM and their common ground relative to changes in working practices. The experiences of the BIM and PLM communities reflected in case study research can be used to understand the practice-based issues challenging each sector. The construction industry is still in the early phases of BIM adoption and therefore it 
stands to benefit most (as a more recent paradigm) in learning from PLM based case studies of professional practice and cultural change. However whilst by comparison the application of PLM in the automotive and aerospace sectors is a more established concept, PLM is still seen as a recent phenomenon in these industries and therefore also stands to benefit from lessons of BIM implementation due to the construction sector's (arguably) more challenging structural and organizational attributes. The paper proceeds with a review of relevant literature that reports on the nature of the practice-based changes triggered by the PLM and BIM concepts relative to new professional activities, roles and responsibilities, knowledge competencies, and stakeholder relationships. The paper then synthesises the changes to professional practice and reflects the two experiences against each other so as to discuss the continuing evolution of professional boundaries and identify lessons for each industry. The paper closes with a summary of perspectives reflected in the literature.

\section{PLM and New Working Practices}

The manufacturing industry has in the past few decades seen rapid advances in the adoption and deployment of PLM. The three fundamental concepts of PLM are to enable: (1) Universal, secure, managed access and use of product definition information; (2) Maintenance of the integrity of that product definition and related information throughout the life of the product; and (3) Management and maintenance of the business processes used to create, manage, disseminate, share, and use the information [3]

\subsection{New Activities}

The PLM concept emerged from Product Data Management (PDM) to primarily manage design files created by CAD tools and since PLM tools consistently evolved in various dimensions [3]. In terms of scope, offered services have expanded to cover not only product definition and design phases but also manufacturing and operations. This expansion has led to PLM systems acting as a hub connecting intangible asset information (i.e. virtual products of design and analysis activities) to physical assets information managed by such systems like Enterprise Resource Planning (ERP) and Customer Relationship Management (CRM). Since the capabilities of PLM systems have been enhanced, it has resulted in new processes, activities and tasks for project engineers, management and administration staff surrounding the capture, management, and preservation of the created information for the entire product portfolio of a company rather than a single project or product as use to be the case.

Consequently a common feature of PLM processes is that implementation requires changes to activities relative to the organization and its systems and conventions [4]. Changes to roles and responsibilities as well as skills and capabilities therefore follow. The implementation of PLM in an organization is therefore an extensive change process which is typically divided and managed in a series of smaller stages [4]. It requires various changes to strategic and operational (process-oriented) level activities as well as to IT system activities. These new activities must be carefully planned and coordinated. To that end, PLM information systems have undergone significant changes and cycles of evolution in the last three decades, from static, closed, standalone routine data processing activities to integrated knowledge and information management for the entire product portfolio. These new activities have been initiated by advances in $\mathrm{CAD} / \mathrm{CAM} / \mathrm{CAE}$, data exchange platforms, visualization tools and modelling systems such as parametric modelling tools [5].

The PLM community have also grown substantially and covers the entire supply chain and extended enterprise which includes designers, suppliers, manufacturing partners, customers and 
other partners. PLM integrates with mechanical, electrical, electronics and software configuration management systems [5]. From such levels of integration new processes, methods and ways of working have emerged, together with new tasks and activities that must be mastered across the product engineering team with new interfaces established between engineering design teams and PLM administrators [6].

\subsection{New Roles and Responsibilities}

PLM focuses on the entire life cycle of a product. As such, PLM isn't the responsibility of just one functional unit or department but rather a whole organization. PLM deployment requires that the PLM implementation team work closely with the cross-functional business teams for example, people from purchasing, order management, sales and marketing, and inventory management [6].

Furthermore, PLM is often an enterprise-wide initiative and requires close integration of products, data, applications, processes, people, work methods, and equipment from across the supply chain [7]. PLM deployment in supply chains raises significant changes to roles and responsibilities and as a result, it is central to deployment initiatives that the roles and responsibilities of a company's product development team be determined at the outset. Likewise responsibilities in relation to partnering companies and their role in the process must be carefully considered [6]. A number of new responsibilities within existing traditional roles can be identified in the PLM literature as well as how these roles are shared between administration executives (typically with an engineering background) and project engineers. Table 1 presents a summary of these new roles).

Traditionally manufacturing approaches do not consider the customer's and supplier's activities as part of the value creation process, and are merely value extracting processes [8]. In a PLM approach a company will more explicitly play some part throughout a product's life and potentially develop a more service-oriented approach.

Table 1. PLM - Changed Roles and New Responsibilities

Role

Project Manager

Responsibility

Business Process Direct implementation resources; Manage project schedules; Track Status; Resolve conflicts and issues

Owner(s)

Provide project priorities and objectives; Direct participation of resources; Resolve business process issues

Subject Matter Experts Communicate current process; Provide information details; Support user community during rollout

IT System Support $\quad$ Support site infrastructure; Extract legacy data; Provide technical expertise

Solution Architect Analyze requirements; Configure application; Develop strategies for product lifecycle collaboration (including collaborative process planning)

Technical Consultant Develop customizations; Provide technical expertise

Service Owner

Delivers and/or utilizes the expected business benefit, Manages service unit to deliver service benefits, Provides Subject Matter Experts to project

\subsection{New Knowledge Competencies}

The shift of perspective from product delivery to a lifecycle approach represents a gap in knowledge for many manufacturing companies $[6,9]$. Teaching institutions and professional bodies are seemingly behind in their alignment of current curriculums, assessments and accreditation relative to the needs of PLM and manufacturing industries. In the US this issue has been widely reported [see e.g., 10]. The call for versatile, cross functional employees that 
remain up-to-date with emerging technologies and are able to tackle the host of new responsibilities associated with through-life requirements and activities is common to both the aerospace and automotive sectors. Hutchins [11], in an editorial, notes that manufacturing professionals in North America are being asked to perform a range of tasks not traditionally included in their professional scope of works. The workforce lacks the capabilities needed to undertake these tasks successfully, and urges more diverse knowledge competencies [11].

The Society of Manufacturing Engineers has been researching "competency gaps" (specific capabilities that companies insist are lacking) and developing a 'Manufacturing Education Plan' [12]. Academia have also responded to the needs of the changing workforce from one that is task oriented to one of that is competency based through the development of innovative curricula, such as Purdue University's initiative to develop a PLM-literate workforce [12]

\subsection{New Relations}

A PLM approach attempts to uncover new relationships and rearrange the value network of actors. The most noticeable change in relations between different parties/stakeholders therefore stems from two fundamental changes to business focus. The first is the change in focus from a traditional product delivery business model to one that centres on the product in use, highlighting the role of the service owner and/or the customer role that the PLM concept is predicated on. This may extend relations of a firm with suppliers or even include new relations with product customers as is the case in a product-service delivery model. The second shift in focus follows on from this and relates to a more strategic approach to intellectual property creation and intellectual property management of a product, from its initial conception to retirement [13 citing 3]. Following on from these two shifts in business focus are a number of secondary factors such as the emergence of networked firms, globalization, changes in the customer base, mass customization, and changes to the mode of production. These factors have accelerated changes in relations between suppliers, manufacturers and customers [14].

IT is the key enabler of PLM support in these new relational networks. However, most case studies report that manufacturing firms are only partially integrated 'islands of information' and still lack a holistic view of 'users of information' [14]. The systems and technologies underpinning the PLM concept are still influenced by low levels of vertical integration [15], a lack of interoperability across complex and disparate tools, and a lack of a 'plug and play' approach to PLM [14]. In an extended enterprise context, a PLM platform must connect product design and analysis processes to production and supply chain processes. Consequently the benefits of PLM can only be realized when horizontal integration of several disparate systems is achieved so as to be able to support wider partnering relations. This requires new approaches to collaboration relative to process planning.

\section{BIM and New Working Practices}

BIM is an emerging technology and collaborative process that in theory should facilitate the digital representation, exchange, use and reuse of all pertinent information about the life cycle of a building or facility from planning, design, construction, FM, and to the ultimate disposal [16]. In practice this is often only partially realised as a range of problems in 'closing the loop' in construction persist in entrenched construction industry practices. Like PLM, as a modeldriven approach to construction, the BIM concept relies on the mastering of new activities, ways of working, and responsibilities surrounding integration and sharing of resources. 


\subsection{New Activities}

Like approaches to PLM, BIM emphasizes open communication and information exchange, collaborative decision making, early participation and contribution of knowledge and expertise by downstream stakeholders (contractors and suppliers), and greater levels of risk sharing [17]. BIM emphasizes integrated processes built around coordinated, reliable information about the life cycle of the facility. Consequently BIM introduces changes in working practices, both within an organization and across organizations [18], which are often difficult and painful.

Changes to collaboration and multidisciplinary teamwork relative to the implementation of BIM have occurred with model-based collaboration and network-based integration now gradually becoming the norm in these environments. The level of interaction is managed differently on projects according to different levels of technical and organizational integration [19]. Higher levels of interdisciplinary interaction and integration are often enabled by colocation arrangements which have spawned concepts such as the "Big Room" [20] and 'knotworking'. Closer interdisciplinary collaboration between AEC stakeholders means that traditional role boundaries are become less distinct, and separations between responsibilities and areas of expertise are diminishing [18]. It also requires new project and technical management activities, such as new process management tasks surrounding the planning and execution of BIM arrangements between stakeholders, and new model management activities surrounding the coordination of discipline specific datasets. New activities are also emerging onsite with the use of 3D and 4D models during fabrication and construction [21]. Most recently the activities of clients and facility managers have also begun to change relative to the deployment of BIM and the use of the as-built model for operations and maintenance [22].

As was the case for PLM, these new AEC and FM activities have been initiated by advances in data exchange standards, new platforms and protocols and improvements to the visualisation and editing of information outside CAD and other modelling systems. Thus the community of users of BIM has also expanded to cover the entire supply chain, which includes designers, suppliers, manufacturing partners, customers and clients. From such new levels of coordination and integration requirements come new processes and collaborative ways of working, new tasks and activities that must be mastered across the design, delivery and operations team. Currently these new interfaces are being established mostly on an ad-hoc basis due to the project-based business focus of the sector.

\subsection{New Roles and Responsibilities}

Traditionally, AEC professionals have taken on separate and more strictly defined roles, delineated by a precise scope of works with established discipline-based responsibilities and contractual agreements. Professional disciplines have sought to transfer risk to other parties formally in contract arrangements [23]. Due to the interdisciplinary nature of BIM, traditional responsibilities relative to management, administrative and functional requirements are being challenged and professional boundaries being temporarily redrawn. Research indicates there is also a lack of clarity on whether these new requirements need to be one role or several, within an organisation or project framework [18].

In many case studies, the introduction of BIM is presented as simply an upgrade in the drawing production process from CAD to BIM. For these projects, the "BIM team", while described as a new function, is effectively an up-skilled version of the CAD operators or manual draftsmen from the pre-BIM project delivery days [19]. In other case studies the need for a new role or roles to implement BIM successfully are documented [24, 25].

The proliferation of roles around BIM implementation may be seen as a reflection of these different approaches and the need for processes to allow different AEC stakeholders to contribute to model development [18]. Whyte [26] suggests that different approaches to 
drawing and model development are to some extent 'institutionalised' in existing professional roles, with architects taking a direct lead in model production, and engineers conducting the fundamental design and analysis but passing instructions to technicians for transformation into the required models, which appears to be causing issues relative to process planning and control. Davies et al. [18] argue that BIM roles within contractor organisations have more freedom to redefine their roles according to their core knowledge competencies. Indeed this seems to be the case where traditional construction management competencies are being updated relative to modelling scheduling (4D) and cost estimates (5D). Contractors appear therefore to be maintaining their own institutional boundaries more readily.

With regard to new professional boundaries, Barison and Santos [27] have identified over 30 different job titles or descriptions for BIM specialists, with further role variations and combinations depending on project size or professional affiliation. A vast variety of new responsibilities on projects mediated by BIM can therefore be seen to be emerging. Table 2 summarizes the new roles and responsibilities identified from the literature.

Table 2. BIM - New Roles and Responsibilities

\begin{tabular}{|c|c|}
\hline Role & Responsibility \\
\hline BIM (Project) Manager & $\begin{array}{l}\text { Including developing a BIM management plan, understanding data exchange } \\
\text { protocols, understanding model progression specifications and document } \\
\text { management. Provide project priorities and objectives; Direct participation of } \\
\text { resources; Resolve business process issues }\end{array}$ \\
\hline BIM Model Managers & Understanding data exchange protocols, Model auditing for model managers \\
\hline $\begin{array}{l}\text { BIM Contract } \\
\text { Administrators }\end{array}$ & $\begin{array}{l}\text { Including new skills in the contractual implications of using } 3 \mathrm{D} \text { models as a } \\
\text { primary source of design information, administration and contract management }\end{array}$ \\
\hline BIM System Support & Support site infrastructure; Extract legacy data; Provide technical expertise \\
\hline Technical Consultant & $\begin{array}{l}\text { Including technical skills relative to building information modelling concepts } \\
\text { (functional basics) as well as functional software skills relative to project } \\
\text { execution, software applications and model authoring }\end{array}$ \\
\hline Client/ Facility Manager & $\begin{array}{l}\text { Analyze operational requirements; specify requirements of as-built BIM model } \\
\text { to be delivered for FM purposes. }\end{array}$ \\
\hline
\end{tabular}

\subsection{New Knowledge Competencies}

There is a large consensus relative to industry requirements for a new set of BIM knowledge competencies. Succar et al. [28] have proposed an integrated definition of BIM competencies which comprise of personal traits, professional knowledge and technical abilities. Across the UK, US and Australia their respective construction industries are calling for the requirements of new abilities, activities or outcomes to be measureable against performance standards so as to hold education, training and/or development offerings to an acknowledged standard.

Numerous BIM knowledge competencies have been categorised into useable clusters and competency taxonomies. [28] include three complementary tiers - core, domain and execution. Competencies across the three tiers are numerous, and potentially thousands of competency items would be required to satisfy the integrated BIM competency definition. The required knowledge competencies can generally be mapped to the new roles and responsibilities that have emerged (illustrated in Table 2). New competencies can be identified relative to coordination and model-based requirements surrounding project management, technical management, technical skills development during project execution, contract administration, systems support through-life, and facilities management knowledge. 


\subsection{New Relations}

The procurement process and contractual arrangements of a project have considerable impact on how BIM is implemented throughout the project team, and therefore on the resulting relations between parties. Under the traditional design-bid-build project framework, BIM is more likely to be used in isolation by a single or a small group of design consultant/s, or in some cases, in the construction stage alone, as there is no incentive or support for more collaborative engagement. More progressive arrangements such as alliancing, partnering, design-build, and most significantly integrated project delivery (IPD) [29] can facilitate and in some cases mandate increased levels of collaboration and greater integration of design and construction roles [18], particularly the increased involvement of contractor/subcontractors in the design phase of the project.

The emerging role of a third-party BIM specialist is also being used to assist different project partners with BIM implementation and modeling processes. While the use of such a person or team has the potential to bridge traditional role divisions or project stages, case studies to date suggest that it is most commonly seen in collaborative project frameworks and procurement methods (e.g., IPD), and not in design-bid-build. This highlights a significant difference between BIM and PLM initiatives where the introduction of a defined administrative PLM team appears to be a more significant and formal process, demanding new relations and where networks must be established with the product engineering team to ensure collaborative process planning and clearly defined data governance strategies .

\section{Comparing BIM and PLM Experiences}

There are a number of key differences between BIM and PLM concepts and their practical deployment. These differences can be seen to stem from the different structures, backgrounds and traditions of their respective industries. A comparison between the AEC and the automotive and aerospace sectors inevitably highlights each industry's unique characteristics and therefore any contrast between BIM and PLM should be mediated by differences in context. The automotive and aerospace sectors are more globalised and consolidated industries; in contrast, the majority of construction projects remain rooted in local contexts and IT adoption is low in a highly fragmented industry [30]. Each sector also differs in terms of their technological intensity, which will in turn effect the implementation of the technology led BIM paradigm versus the product-driven PLM paradigm across their industries' respective supply chains. Further, due to the unique nature of construction, the project-centric companies that characterise this sector focus on issues of integration and transparency across multiple disciplines and organisational boundaries in their use and management of model-based technologies. Consequently requirements relative to data governance and model management centre on discipline-specific tools, activities and representations [17]; knowledge and information management is therefore also challenged by lower levels of technological sophistication throughout the construction supply chain. In the product-centric companies that characterise the automotive and aerospace sectors, the focus is instead on the overall business process and due to a more consolidated industry an enterprise level perspective can be fostered more readily. Thus PLM applications in these sectors have gained higher levels of traction due to the nature of a limited client base and higher levels of supplier specialisation and technological expertise. This in turn has caused suppliers to compete on technical expertise rather than on cost efficiency as is still the case in BIM-enabled construction.

In the last decade, widespread efforts have been undertaken to enhance various aspects of BIM platforms from their focus on internal modelling capabilities and software interoperability, to expand BIM's role to the entire lifecycle of a built asset. BIM servers [31] are now being 
developed to provide a large integrated data- and knowledge-base that can be leveraged not only in design and engineering but also in planning and management of component fabrication, construction operations, and facilities maintenance. Hence, BIM's scope, functionality and value are only recently being expanded from merely modelling and visualization to a platform for collaborative processes and resourceful decision-making, aiming to support a whole life cycle approach. In contrast, PLM solutions have been serving as the basis for collaborative product definition, manufacturing, and service management for the past decade. PLM services have traditionally been provided for the automotive and aerospace industries but the demand for them has gradually expanded to include a broader range of manufacturing industries. With PLM, companies think of the standard processes, standard data and standard systems that they, and the numerous suppliers, customers, and partners, can use to save an enormous amount of time and money [7]. A lack of process commonality and standardization usually results in nonstandardized and suboptimal PLM implementations with a high cost of ownership being passed to companies implementing such process-oriented integrations [5]; with this being a key lesson for the construction sector. The support of PLM requires collaborative harmonization of a set of complementary and interoperable open standards and open source models that cover the full range of aspects of the products' life cycle [15]. However even from a PLM perspective, the industry standards available for CAD systems are not yet widely accepted and popular as a useful form of data storage due to the lack of information they can hold [13]. Importantly, data exchange standards have often been criticized for their inability to capture well-defined business processes, work flow patterns/ systems, and underlying business rules. For organizations of any sector, a key issue in the implementation of PLM or an FM-focused BIM deployment is the transition processes required in adopting new solutions, i.e. moving from the old to the new system. There are technical issues, such as schema evolution, business rules phasing (old rules/policies to new rules/policies), data migration, customization, system maintenance, etc. [4]. For this reason collaborative process planning is crucial.

In considering the transition process surrounding PLM and BIM deployment another key lesson for practitioners concerns the fostering of new attitudes and perspectives towards collaboration and shared responsibility relative to implementation. PLM and BIM implementation must be driven by the requirements of product design processes rather than IT considerations, and therefore the bill of materials or product structure must remain at the centre of these process requirements. Such a perspective is arguably more difficult for AEC professionals to foster. Currently the main perception of the construction industry relative to BIM implementation challenges centres on answering many of the same data exchange, business process and policy phasing problems that have faced PLM deployment. Yet this is only part of the problem and despite the documented changes to AEC roles and responsibilities BIM implementation is driven by IT considerations. Instead practitioners should be driven by the requirements of the product design process and focus on implementing a unifying solution that enables information and processes to be to acquired, managed and utilised across various project and enterprise level systems. AEC practitioners may therefore see further changes to their newly emerging roles and responsibilities. As BIM maturity levels increase the common end point with PLM may be able to be realised with the construction industry moving towards rationalisation - including higher levels of consolidation and harmonisation in collaborative ways of working, increased use of IPD type procurement methods, and higher levels of collaborative process planning. From this perspective, the responsibilities that have emerged alongside PLM solutions (see Table 1); may begin to emerge in the construction industry and indeed if the value of BIM as a lifecycle management concept is to be realised, then these PLM responsibilities will eventually emerge. 


\section{Conclusions}

This research provides an analysis of related literature on how PLM and BIM impact on the traditional activities of the manufacturing industries of the automotive and aerospace sectors and those of the construction sector. The influence of these activities relative to changes in roles and responsibilities of professionals, their relationships and scope of services within the project and organizational contexts were also reviewed. This comparison of the two concepts aims to provide better understanding into the changing nature of professional practice and may provide useful insights for evaluating PLM and BIM implementations relative to people and cultural change. There are only a few documented efforts of implementing PLM systems in the AEC companies [see 33, 34]. Previous research has also mapped PLM system functionality to existing and as yet unmet challenges facing BIM deployment [1]. From this perspective, the integration gaps relative to BIM technologies and information management have been demonstrated. However whilst PLM functionalities may be able to bridge a number of gaps in the construction sector's application of BIM, issues surrounding professional practice and cultural change are continuing to plague the adoption of these methods in both sectors. Consequently controlling the changes to practice identified in the literature are critical to transition processes and must be planned for with appropriate training, education, and management commitment. A useful direction for future research is to investigate how these industries are developing training, education, and management initiatives to support PLM and BIM deployment.

\section{References}

1. Jupp, JR (2013), Incomplete BIM implementation: Challenges and role of product lifecycle management functions, in B. Alain, R. Louis, D. Debasish, (eds.) Product Lifecycle Management for Society, IFIP Adv in Inf. and Comm. Tech., Vol. 409, pp. 630-640, Springer Berlin Heidelberg.

2. Ford, G, Bartley, T, Igba, J, Turner, A, \&McMahon, C (2013), Product Life Cycle Data Management: A Cross-Sectoral Review, in B. Alain, R. Louis, D. Debasish, (eds.) Product Lifecycle Management for Society, FIP Adv in Inf. and Comm. Tech., Vol. 409, pp. 58-67.

3. CIMdata (2014). All About PLM, retrieved Feb 2014 from: http://www.cimdata.com/en/resources/about-plm

4. Kärkkäinena H., Myllärniemia, J., Okkonena J., \& Silventoinenb, A (2009) Assessing Maturity Requirements for Implementing and Using Product Lifecycle Management, The 9th International Conference on Electronic Business, Macau, Nov 30 - Dec. 4. pp 669-678

5. Rangan, R.M. Rohde, S.M. Peak, R. Chadha, B. Bliznakov, P. (2005) Streamlining product lifecycle processes: a survey of product lifecycle management implementations, directions, and challenges, Journal of Computing and Information Science in Engineering 3 227-237.

6. Hewett, A, (2009) Product Lifecycle Management (PLM): Critical Issues and Challenges in Implementation, Inf. Tech. and Product Dev., Annals of Inf. Sys., Vol. 5, No. 1, pp.81-105.

7. Stark, J. (2011). Product lifecycle management: $21^{\text {st }}$ century paradigm for product realisation, $2^{\text {nd }}$ ed., Decision engineering, Springer.

8. Prahalad C.K. \&Ramaswamy V. (2004) Co-creation experiences: The next practice in value creation. Journal of Interactive Marketing, 18(3): 5.

9. Ericson $\AA$. \&Larsson T. (2005) A service perspective on product development - towards functional products. In 12th Intl. Product Dev. Mgmt. Conf., CBS, Copenhagen.

10. ACT Inc. (2011), A better measure of skills gaps: Utilizing ACT Skill profile and assessment data for strategic skill research. Retrieved (Feb 2014) from www.act.org/research/policymakers/reports/abettermeasure.html

11. Hutchins, G. (2004). SME Speaks: Manufacturing Engineers Must Reduce Competency Gaps. Manufacturing Engineering magazine 132(2). Retrieved(Feb. 2014) from www.sme.org/MEMagazine/Article.aspx?id=31088\&taxid=1427 
12. Fillman, S.A., Wilde, K. L., Kochert, J.F., Homan, S.R., \& Tomovic, C.L. (2010). Entrylevel engineering professionals and product lifecycle management: a competency model, Int. J. of Manufacturing Technology and Management, 13(3/4), 306-311.

13. Cheung, W. M. \&Schaefer, D. (2010). Product lifecycle management: state-of-the-art and future perspectives, In M. Cruz-Cunha (Ed.), Enterprise Information Systems for Business Integration in SMEs: Technological, Organizational, and Social Dimensions, pp. 37-55, Hershey, PA: IGI Global.

14. Subrahmaniam, E., Rachuri, S., Fenves, S. J., \& Foufou, S. (2005). Product lifecycle management support: a challenge in supporting product design and manufacturing in a networked economy. International Journal of Product Lifecycle Management, 1(1), 4-25.

15. Rachuri, S., Subrahmanian, E., Bouras, A., Fenves, S. J., Foufou, S., \& Sriram, R. D (2008). Information sharing and exchange in the context of product lifecycle management: Role of standards. Computer-Aided Design, 40(7), 789-800.

16. Eastman, C., Teicholz, P., Sacks, R., \& Liston, K. (2008). BIM Handbook: A Guide to Building Information Modeling, for Owners, Managers, Designers, Engineers, and Contractors. Hoboken, New Jersey: John Wiley \& Sons.

17. Rezgui, Y., Beach, T., \& Rana, O. (2013). A governance approach for BIM management across lifecycle and supply chains using mixed-modes of information delivery. Journal of Civil Engineering and Management, 19(2), 239-258.

18. Davies, C, McMeel, D, Wilkinson, S. (2013) Mapping roles in an altered landscape - The impact of BIM on designer-constructor relationships, CIB W78 30th International Conference on Applications of IT in the AEC Industry. 9-12 October 2013; Beijing, China.

19. Merschbrock, C. (2012). Unorchestrated symphony: The case of inter-organizational collaboration in digital construction design. J. of Inf. Tech in Const. (ITcon), 17, 333-350.

20. Cohen, J. (2010). Integrated project delivery: Case studies. Sacramento, CA: AIA. Retrieved (Feb 2014)www.aia.org/aiaucmp/groups/aia/documents/pdf/aiab082051.pdf

21. Davies, R., \& Harty, C. (2013). Implementing "Site BIM": A case study of ICT innovation on a large hospital project. Automation in Construction, 30, 15-24

22. Sabol, L. (2008), Building information modeling and FM, IFMA World Workplace.

23. Hughes, W., Champion, R., \& Murdoch, J. (2007). Construction contracts: law and management. Routledge.

24. Rowlinson, S., Collins, R., Tuuli, M. M., \& Jia, Y. (2010). Implementation of BIM in Construction: A comparative case study. 2nd Intl. Symp. on Comp Mech/12th Intl. Conf. on Enhmt. and Prom. of Comp. Methods in Eng. and Sci. AIP, pp. 572-577.

25. Sebastian, R. (2011). Changing roles of the clients, architects and contractors through BIM. Engineering, Construction and Architectural Management, 18(2), 176-187.

26. Whyte, J. (2011). Managing digital coordination of design: emerging hybrid practices in an institutionalized project setting. Engineering Project Organization Journal, 1(3), 159-168.

27. Barison, M. B., \& Santos, E. T. (2010). An overview of BIM specialists. In W. Tizani (Ed.), Proceedings of the International Conference on Computing in Civil and Building Engineering, pp 141, UK: Nottingham University Press.

28. Succar, B, Sher W, Williams, A (2013), An integrated approach to BIM competency assessment, acquisition and application, Automation in Construction, 35, 174-189.

29. American Institute of Architects. (2007). Integrated Project Delivery: A Guide. CA Council.

30. Green, S.D., Newcombe, R., Fernie, S. \& Weller, S. (2004) Learning across business sectors: Knowledge sharing between aerospace and construction, University of Reading.

31. Beetz, J., van Berlo, L., de Laat, R., \& Bonsma, P. (2011). Advances in the development and application of an open source model server for building information. Proc. of CIB W078-W102, Sophia Antipolis, France.

32. Koppinen, T. (2012). The PLM journey at Skanska [Webinar]. Retrieved (Feb 2014) from http://live.plminnovation.com/w/333/the plm journey at skanska.html

33. Aram, S. and Eastman, C (2013), Integration of PLM solutions and BIM systems for the AEC industry, Proceedings of the 30th Intl. Symp. of Automation and Robotics in Construction, Montréal, pp. 1046-1055.

34. Pöllä, M. (2010). Skanska Finland: Improving cost control with Enovia V6. Dassault Systèmes, Retrieved (Feb, 2014) from www.3ds.com/fileadmin/COMPANY/CUSTOMERSTORIES/PDF/Skanska-Finlandflyer- English.pdf 